\title{
LA PROHIBICIÓN DE LA TORTURA Y DE PENAS Y TRATOS INHUMANOS O DEGRADANTES EN EL CEDH
}

\author{
RAÚL CANOSA USERA \\ Catedrático de Derecho Constitucional \\ Universidad Complutense
}

\begin{abstract}
SUMARIO
I. La protección parcial de la integridad sin reconocimiento expreso de un derecho. II. El derecho a no sufrir torturas ni penas o tratos inhumanos o degradantes. III. Tratos vedados: la escala de la gravedad. IV. Deber de proteger y derecho a la protección. V. Un intento de ordenación de la casuística jurisprudencial: ámbitos de la realidad en los que se ha proyectado el artículo 3. VI. Conclusión.
\end{abstract}

\section{LA PROTECCIÓN PARCIAL DE LA INTEGRIDAD SIN RECONOCIMIENTO EXPRESO DE UN DERECHO}

\section{I.1. Raigambre histórica de la prohibición de torturas, penas y tratos inhumanos o degradantes}

El artículo 3 del Convenio Europeo de Derechos Humanos $(\mathrm{CEDH})^{1}$ continúa la tradición humanitaria que inaugura el constitucionalismo liberal al prohibir la tortura y

1 Entre los comentarios del artículo 3 CEDH cfr. G. CoHEn-Jonathan, Aspects européens des droits fondamentaux, Montchrestien, Paris, 1996, pp. 70 y ss. P. KempeEs, A sistematic guide to the case-law of European Court of Human Rights 1960-1994, Martinus Nijhoff Publishers, Boston-Londres, 1996, pp. 13 y ss. A. SALAdo, «La tortura y los tratos prohibidos por el Convenio (art. $3 \mathrm{CEDH}$ )», en J. García Roca y P. SANTOlaya Machetti (coords.), La Europa de los derechos. El Convenio europeo de Derechos Humanos, CEPC, Madrid, 2014, pp. 85 y ss. R. BEDDARD, Human Rights and Europe, Grotius Publications, Cambridge University Press, 1995, p. 45, y Di Andreana Esposito, «Art. 3», en S. Bartole, G. P. Conforti y B. Raimondi (dir.), Comentario alla Convenzione Europea per la tutela dei diritti dell'uomo e della libertà fondamentali, CEDAM, Padova, 2001, p. 49. F. Sudre, «Article 3», en L. E. PetTiti, E. Decaux y P. H. Imbert (dirs.), La Convention Européenne des Droits de l'bomme article par article, , Economica, Paris, 1995 , p. 157, A. CASSESE, «Prohibition of Torture and Inhuman or Degrading Treatment or Punishment», en The European System for the Protection of Human Rights, Martinus Nijhoff, Dordrecht/Boston/London, 1993, p. 228; R. McDonald, «International Prohibition Againts Torture and Other Forms of Similar Treatement or Punishment», en International Law at a Time of Perplexity/ Esays in honor of Shabtain Rossenne, Martinus Nijhoff, Dordrecht/Boston/ London, 1988, p. 27. J. CALlEWAERT, «L'article 3 de la Convention Européene: une norme relativement absolute 
que tiene su manifestación señera en el Bill of Rights de 1689 cuyo artículo X establece «que no deben exigirse fianzas exageradas ni imponerse multas excesivas ni aplicarse castigos crueles ni desacostumbrados.» Casi en los mismos términos, prohibiendo los «castigos crueles e inusitados», se expresa la octava enmienda, aprobada en 1792, a la Constitución de los Estados Unidos de 1787.

Por su parte, el constitucionalismo europeo actualizó la terminología y el artículo 9 de la Declaración de derechos del hombre y del ciudadano de 1789 prohíbe «todo rigor que no sea necesario para mantenerlo retenido debe ser severamente reprimido por la ley», y también el artículo 303 de la Constitución española de 1812 disponía: «no se usará nunca del tormento ni de los apremios.» ${ }^{2}$

El Derecho constitucional histórico introdujo pues desde la primera hora interdicciones claras a lo que hoy denominamos torturas o tratos inhumanos, y fijó así un ámbito de la integridad personal protegido frente al poder público, en línea con el resto de los derechos públicos subjetivos. Sin embargo, el expediente técnico usado no fue el de reconocer expresamente un derecho, sino el de prohibir a los poderes públicos determinadas acciones que, aún recibiendo nombres distintos, remiten a las actuales de tortura y tratos inhumanos o degradantes. Sea cual fuere la nomencaltura empleada para referirse a los tratos vedados, el modo de combatirlos ha sido siempre el de la prohibición objetiva, pero ésta tenía que abrir la puerta a la reclamación subjetiva de la víctima.

En el discurrir histórico de los derechos era lógico que el Derecho internacional ${ }^{3}$, al ocuparse de ellos, incorporase también la prohibición que estamos analizando. Por eso ya el artículo 5 de la Declaración de Derechos Humanos de Naciones Unidas (1948) la recogía. Siguió el Convenio Europeo (1950), con su artículo 3. Posteriormente, en 1962, la Convención Americana (artículo 5) y el Pacto de Derechos Civiles y Políticos de Naciones Unidas de 1966 (artículo 7), sin olvidad los tratados específicos ${ }^{4}$.

Hay pues coincidencia en incluir la prohibición de la tortura en todos los ordenamientos tanto internacionales como nacionales, así como en la Carta de Derechos Fundamentales de la Unión Europea (artículo 4)

\section{I.2. Interpretación evolutiva de la prohibición}

Es obvio que lo que hoy significan los «tratos crueles o inusitados» o las torturas y los tratos inhumanos o degradantes ha ido evolucionando con el tiempo y determinadas acciones que antaño no hubieran recibido tal calificación hoy la reciben ${ }^{6}$. En este sentido

ou absolument relative?», en Liber Amicorum Marc-AndréEissen, Bruylant, Paris, 1995, pp. 13 y ss. W. ScHABAs, The European Convention on Human Rigths, Oxford University Press, 2015, pp. 43 y ss. Un estudio extenso y sistemático de la jurisprudencia del TEDH lo ofrece J. BARCELONA LLOP, La garantía europea del derecho a la vida y a la integridad personal frente a la acción de las fuerzas del orden. Estudio de la jurisprudencia del TEDH sobre los artículos 2 y 3 del Convenio Europeo para la Protección de DDHH, Civitas, Madrid, 2007.

2 Un panorama de estos antecedentes lo ofrece R. CANOSA UsEra, El derecho a la integridad personal, Lex Nova, Valladolid, 2006, pp. 19 y ss.

3 Ibid., pp. 23 y ss.

4 Cfr. infra II y III.

5 Ibid., pp. 48 y ss.

6 Acerca de esta interpretación evolutiva, cfr. entre otros F. SUDRE, Droit européen et international des droits de l'homme, PUF, París, 2005, pp. 288 y ss. También R. CANOSA UsERA, «La interpretación evolutiva del convenio 
es célebre, por ejemplo, la jurisprudencia de la Corte Suprema de los Estados Unidos o, en lo que ahora nos atañe, la del Tribunal Europeo de Derechos Humanos (TEDH). De este último son relevantes los casos en los que, tras destacarse que el Convenio es un instrumento vivo, se anuncia un cambio en la jurisprudencia para adaptarla a la nueva sensibilidad social que, en relación con las torturas y tratos inhumanos, es cada vez menos tolerante y provoca una ampliación jurisprudencial del ámbito protegido ${ }^{7}$. Lo anterior significa que situaciones de la vida antes no cubiertas por la provisión, ahora lo están. Esto sucedió en relación con las torturas a partir del caso Ascoy c. Turquía, de 18 de diciembre de 1996, cuando comienza a evolucionar su jurisprudencia que cambia definitivamente en el caso Selmouni c. Francia, de 28 de julio de 1999, incrementando su estándard de protección.

Por lo que concierne a los tratos inhumanos o degradantes, la más significativa y explícita ampliación de la protección acontece en los casos Henaf c. Francia, de 27 de noviembre de 2003, y Yankov c. Bulgaria, de 10 de diciembre de 2003. En ellas el TEDH subió el estándard de protección respecto de lo que considera trato inhumano ${ }^{8}$. Consideró que había vulneración, en el primero de los casos, por encadenar durante una noche a la cama de un hospital a un preso multirreincidente y con antecedentes de quebrantamiento de permiso carcelario, y en el segundo por el afeitado de la cabeza de un detenido, acción en la que encuentra ánimo de humillar. Esta evolución, obedece, como afirma en la primera de las sentencias citadas, a que la Convención es un instrumento vivo que hay que interpretar a la luz de las circunstancias actuales que el creciente nivel de exigencia en materia de protección de los derechos implica, y, en paralelo, una mayor firmeza en la apreciación en los atentados contra los valores fundamentales de las sociedades democráticas, lo que hace que entren en el campo de aplicación del artículo 3 conductas que en el pasado se hubiera considerado que no presentaban el grado mínimo de gravedad.

En contraste, en el caso Pretty c. Reino Unido, de 29 de abril de 2002, el TEDH negó que hubiera infracción del artículo 3 en la negativa de las Autoridades a garantizar la impunidad al marido de una enferma terminal que deseaba morir, pero no podía suicidarse y necesitaba la ayuda de su marido. Según la recurrente se la obligaba a soportar una lenta agonía que, a su juicio, constituía trato inhumano o degradante. De este caso se infiere la evidente consecuencia de que, si bien los justiciables pueden impulsar los cambios en la doctrina del TEDH, éste siempre es dueño de materializarlos o no, modulando así la evolución de su jurisprudencia.

En el contexto de esta perenne evolutividad no puede olvidarse la invención de la doctrina de la violación procedimental que se suma a la de la ampliación del ámbito

Europeo de Derechos Humanos», en J. García Roca y P. Fernández SÁnChEz, Integración europea a través de derechos fundamentales, CEPC, Madrid, 2009, pp. 79 y ss. J. CASADEval habla de «interpretación extensiva y evolutiva», El Convenio Europeo de Derechos Humanos. El Tribunal de Estrasburgo y su jurisprudencia, Tirant lo Blanch,Valencia, 2012, pp. 135 y ss.

7 Sobre esta ampliación, cfr. R. Canosa Usera, H. Fix Zamudio, y E. Corzo, «El derecho a la integridad personal», en J. García Roca, P. Fernández, P. SANTOlaya, y R. Canosa (edit.), El diálogo entre los Sistemas Europeo y Americano de Derechos Humanos, Civitas, Madrid, 2012, pp. 26 y ss. También VELU y ERGEC analizan los distintos ámbitos donde el TEDH ha proyectado su doctrina, La convention européenne des droits de l'bomme: extrait du repertoire du droit belge, ob. cit., pp. 204 y ss.

8 Sobre estos dos casos, cfr. Canosa Usera, El derecho a la integridad personal, ob. cit., p. 32. 
material; en efecto cuando el Estado no investiga suficientemente la violación alegada se entiende que faltó diligencia en la investigación y ello constituye en sí mismo una violación ${ }^{9}$.

La evolución comentada ha implicado que la parte de la integridad personal protegida por la prohibición contenida en el artículo $3 \mathrm{CEDH}$ sea mayor. A pesar de esta ampliación, el TEDH no puede con el artículo 3 tutelar todo el bien jurídico integridad personal ${ }^{10}$. El problema mayor del TEDH es que no dispone de un precepto convencional específico, en contraste con la Corte Interamericana de Derechos Humanos que tiene a su disposición el artículo 5 de la Convención Americana que proclama expresamente el derecho a la integridad ${ }^{11}$. Para paliar esta desventaja el TEDH ha acabado adscribiendo el derecho a la integridad al artículo $8 \mathrm{CEDH}$, es decir, considerándolo parte del derecho a la vida privada y familiar ${ }^{12}$. Lo ha hecho además refiriéndose claramente al «derecho a la integridad» ${ }^{13}$, sin enmascararlo. De esta suerte, aún sin reconocimiento expreso en el Convenio de un derecho específico a la integridad el TEDH acaba protegiendo la integridad frente a ataques contra ella que no caen en la órbita del artículo 3. Así que la protección de la integridad frente a torturas y penas y tratos inhumanos y degradantes derivaría del artículo $3 \mathrm{CEDH}$, con un ámbito cada vez más amplio, y frente otros ataques a la integridad la salvaguardia se encauza a través del artículo 8. El TEDH ha desplegado una auténtica interpretación evolutiva respecto a la ampliación de las situaciones de la vida protegidas por el artículo 3, además de la tesis de la violación procedimental, y ha creado un derecho a la integridad, incluido en el artículo 8, para proteger la integridad en aquellas otras múltiples situaciones vitales donde los ataques o riesgos para ella no merecieran reproche desde la óptica del artículo 3.

\section{EL DERECHO A NO SUFRIR TORTURAS NI PENAS O TRATOS INHUMANOS O DEGRADANTES}

La generalizada inclusión de la prohibición es indicativa de que la prohibición forma parte del acervo común de todo orden jurídico fundado en la libertad. Sería uno de esos derechos cuya tutela sería imprescindible a la luz del célebre artículo 16 del la Declaración francesa de 1789. En el ámbito estatal, la sanción penal de las conductas proscritas completa la protección. Además, hay que subrayar que el castigo penal es también una

9 Cfr. infra III.

10 Canosa Usera, El derecho a la integridad personal, ob. cit., pp. 39 y ss.

11 En contraste con la Convención Americana de Derechos Humanos, el Pacto de San José, al respecto cfr. sobre todos S. García Ramírez, Los derechos bumanos y la jurisdicción interamericana, Universidad Nacional Autónoma de México, 2002. S. García Ramírez (coord.), La jurisprudencia de la Corte Interamericana de Derechos Humanos, Instituto de Investigaciones Jurídicas, UNAM, México, 2001. L. Burgorgue-Larsen y A. Úbeda De Torres, Las decisiones básicas de la Corte Interamericana de Derechos Humanos, Civitas, Madrid, 2009. También H. FaúnDEZ LEDESMa, El sistema interamericano de protección de los derechos humanos. Aspectos institucionales y procesales, San José de Costa Rica, 1996. L.I. SÁNCHEZ RoDRíGUEZ, «Los sistemas de protección americano y europeo de derechos humanos», en La Corte y el sistema internacional de Derecho Humanos, San José de Costa Rica, 1994, pp. 501 y ss.

12 A propósito de la conexión con el artículo 8 de la protección de la integridad, cfr. P. SANTOLAYA MaCHETTI, en La Europa de los derechos. El Convenio Europeo de Derechos Humanos, ob. cit., 2014, pp. 429 y ss. Y CANOSA UsERA, El derecho a la integridad, ob. cit., pp. 117 y ss.

13 Caso Glass contra Reino Unido, de 9 de marzo, parágrafo 70. 
exigencia del Derecho internacional, en concreto del artículo 4 de la Convención contra la tortura y otras penas o tratos crueles, inhumanos o degradantes, de 10 octubre 1984.

Ya apuntábamos que el artículo $3 \mathrm{CEDH}$ no proclama en rigor un derecho ${ }^{14}$, sino que contiene una prohibición para los poderes públicos de infligir tortura o tratos inhumanos o degradantes. Para algunos ${ }^{15}$ el artículo 3 supone un reconocimiento negativo del derecho a la integridad. Y es innegable que el bien jurídico protegido es, en efecto, la integridad personal y que, al proscribirse ciertas acciones, acaba perfilándose negativamente el contenido de un derecho a no ser sometido a torturas o tratos inhumanos o degradantes. La proscripción objetiva de tales conductas lesivas del bien jurídico integridad acaba generando un derecho subjetivo a no sufrir los tratos vedados. La subjetivación se consagra con la posibilidad de hacer valer judicialmente esa posición individual que resulta, por reflejo, de la prohibición objetiva.

Este derecho subjetivo reflejo no es el único de los que forman el contenido del derecho a la integridad. Es un fragmento del haz de posiciones iusfundamentales que componen la totalidad del derecho a la integridad. Sin embargo, es uno de los más fuertes porque recibe del orden jurídico, internacional y nacional una protección más intensa, al punto de ser considerado absoluto e inderogable. ${ }^{16}$ Lo ha resaltado el TEDH, entre otros, en el caso Soering c. Reino Unido, de 7 de julio de $1989^{17}$, en el que el TEDH subrayó también que este precepto conforma uno de los valores fundamentales de las sociedades democráticas ${ }^{18}$.

Así que la prohibición contenida en el artículo 3 del Convenio es absoluta, es decir, el derecho que genera no puede ser limitado ni suspendido; es, pues, inderogable, tal y como establece el artículo 15.2 CEDH. No cabe, por tanto, ponderar entre situaciones de tortura o tratos inhumanos y otros bienes jurídicos como, por ejemplo, la eficacia policial

$14 \mathrm{Al}$ respecto G. Cohen-Jonathan, Aspects européens des droits fondamentaux, ob. cit., pp. 70 y ss., y también P. Kempees, A sistematic guide to the case-law of European Court of Human Rights 1960-1994, ob. cit., 1996, pp. 13 y ss. Esta estructura de prohibición no de reconocimiento de un derecho la comparte el artículo 3 con el artículo 4 (la prohibición de esclavitad), como subraya S. Greer, The Europena convention of Human Rights. Achievement, Problems and Prospects, Cambridge University Press, 2006, pp. 232. critica la consideración de absoluto del derecho a la vista de las contradicciones en las que a su juicio in curre el TEDH.

15 A. Salado, ob. cit., p. 87.

16 Son muchos los que han afirmado el carácter absoluto e inderogable de la prohibición contenida en el artículo 3 CEDH, por ejemplo, Cohen-Jonathan, Aspects européens des droits fondamentaux, ob. cit., pp. 70 y ss., y también KeMPeES, A sistematic guide to the case-law of European Court of Human Rights 1960-1994, ob. cit., 1996, pp. 13 y ss.; SUDRE, «Article 3», en La Convention Européenne des Droits de l'homme article par article, ob. cit., p. 157, CASSESE, «Prohibition if Torture and Inhuman or Degrading Treatment or Punishment», ob. cit., p. 228; McDonald, «International Prohibition Againts Torture and Other Forms of Similar Treatement or Punishment», ob. cit., p. 27; J. CALLEWAERT, «L'article 3 de la Convention Européene: una norme relativement absolute ou absolument relative?», ob. cit., p. 45, y Di ANDREANA EsPosito, «Art. 3», ob. cit., p. 49. En la doctrina española, cfr. P. Santolaya Machetti, El derecho de asilo en la Constitución española, Lex Nova, Valladolid, 2001, pp. 136 y 137, y SALAdo Osuna, ob. cit., p. 87. J. BARCELONA Llop, La garantía europea del derecho a la vida y a la integridad personal frente a la acción de las fuerzas del orden, ob. cit., pp. 43 y ss. GREER, The Europena convention of Human Rights. Achievement, Problems and Prospects, ob. cit., pp. 233 y ss. critica la consideración de absoluto del derecho a la vista de las contradicciones en las que a su juicio incurre el TEDH, aunque admite que posee un status de especial protección.

$17 \mathrm{Al}$ respecto cfr. Sudre, Droit européen et international des droits de l'homme, ob. cit., p. 281, que cita el también relevante, a estos efectos, caso Al-Adsan c. Reino Unido, de 21 de noviembre de 2001, en el que se dice que la prohibición de la tortura se ha convertido en una regla interpretativa de Derecho internacional.

18 Como subrayan P. VAN DijK, F. VAN Hoof, A. VAN Rijn y L. ZwaAK (eds.), Theory and Practice of the European Convention on Hiuman Rights, Intersentia, Antwerpen-Oxford, 2006, p. 88. 
en la lucha contra el terrorismo ${ }^{19}$. Ningún fin, por legítimo que sea, permite someter a un individuo a torturas, penas y tratos inhumanos o degradantes, pues el valor supremo de la dignidad sufre siempre en semejantes situaciones.

\section{TRATOS VEDADOS: LA ESCALA DE LA GRAVEDAD}

Para distinguir entre los distintos tratos vedados por el artículo 3, el TEDH ha recurrido a la Convención contra la tortura o penas crueles, inhumanas o degradantes de Naciones Unidas, de 10 de diciembre de1984, además de al Convenio europeo para la prevención de la tortura de las penas y tratos inhumanos o degradantes, de 1987. Pero mientras que la específica Convención americana tiene carácter sustantivo y complementa la prohibición del Pacto de San José, estableciendo medidas para combatirla y sancionarla ${ }^{20}$, el Convenio europeo se limita a crear el Comité para la prevención de la tortura y los tratos prohibidos, Comité cuyos informes son con mucha frecuencia citados por el TEDH, así que, como en otras ocasiones, el TEDH incorpora a su canon de enjuiciamiento otros tratados más específicos y considera la opinión de los órganos encargados de interpretarlos, todo ello para fijar el alance de los derechos del CEDH.

Con los malos tratos en general el TEDH conformó una escala de gravedad ${ }^{21}$ dentro de la cual la conducta de mayor gravedad es la tortura, de conformidad con el grado que le ha otorgado la jurisprudencia, y después le siguen las penas y los tratos crueles, inhumanos o degradantes. Cada uno de estos tres grados pertenece a una misma escala y se distinguen entre sí por la gravedad. Sin embargo, no hay una diferencia clara entre los tratos inhumanos y los degradantes, a pesar de que el TEDH intentó establecer un criterio clasificatorio de la gravedad y las circunstancias que hay que valorar en cada una de las conductas para diferenciarlas entre $\mathbf{s i}^{22}$. Estas distinciones se han ido desdibujando, dejando aparte la más clara diferenciación entre la tortura y los demás tratos vedados ${ }^{23}$. Así pues, el TEDH no ha

19 Caso Tomas c. Francia, de 27 de agosto de 1992 y caso Ascoy c. Turquía, de 18 de diciembre de 1996.

20 Existe, de entrada, una diferencia en la regulación textual de las diversas conductas prohibidas y su escala. Mientras que en la CEDH (art. 3) se hace referencia, únicamente en sentido negativo, a la tortura y a los tratos inhumanos y degradantes, en la CADH (art. 5), a la misma fórmula en sentido negativo se añade la referencia a los tratos crueles y, en sentido positivo, se adiciona el trato digno. No obstante, la diferente regulación, encontramos varias coincidencias en la jurisprudencia. Cfr. al respecto CANOSA, Fix Zamudio y Corzo, ob. cit., pp. 162 a 168.

21 Acerca de la escala de gravedad de las conductas prohibidas por el artículo 3 CEDH, cfr. Di ANDREANA Esposito, ob. cit., p. 56 y ss. J. Velu y R. ERGEC, La convention européenne des droits de l'bomme: extrait du repertoire pratique du droit belge, tom. VII, Bruyllan, Bruselas, 1990, pp. 195 y 196. CaSadeval, El Convenio Europeo de Derechos Humanos. El Tribunal de Estrasburgo y su jurisprudencia, ob. cit., p. 217. VAN DijK, Van Hoof, Van Rijn Y ZWAaK (eds.), Theory and Practice of the European Convention on Hiuman Rights, ob. cit., 2006, pp. 406 y ss.

22 Este esfuerzo no lo encontramos en América, donde se ha optado por la casuística, predominando la ambigüedad en la calificación de las conductas. Aunque a diferencia de Europa se ha introducido un elemento más que, si bien lo anunciamos en sentido positivo, trato digno, ha jugado un papel importante a la hora de la calificación de las conductas al referírselo como trato indigno. CANOSA, Fix Zamudio y Corzo, ob. cit., pp. 162 a 168.

23 Parte de la doctrina critica la concepción relativista que deja en manos de la jurisprudencia la determinación casuística de cuándo está presente: C. VILLÁN DURÁN, «La Convención contra la tortura y su contribución a la definición del derecho a la integridad física y moral en Derecho Internacional», en Revista Española de Derecho Internacional, 1985, vol. XXXLII, p. 390. SALADO, «La tortura y otros tratos prohibidos por el Convenio (art. 3 CEDH)», ob. cit., pp. 89 y 90 . 
sostenido este esfuerzo clasificatorio y ha acabado diluyendo la distinción entre tratos inhumanos y tratos degradantes para limitarse a declarar la infracción del artículo 3 del Convenio o declarar que en el caso se dan tanto el trato inhumano como el degradante ${ }^{24}$.

Todos los tratos vedados constituirían ataques a la integridad y por ello a la dignidad. Tendrían en común el efecto de causar algún tipo de sufrimiento que provocase a la víctima humillación ${ }^{25}$. Según las circunstancias del caso, habría que valorar la gravedad, y de esta valoración resultaría la calificación del trato infligido como tortura, trato inhumano o trato degradante. El criterio de la gravedad, así como las circunstancias que sería necesario valorar en cada supuesto, las expone el TEDH en el importantísimo e inaugural caso Irlanda c. Reino Unido, de 18 de enero de $1978^{26}$. Para el TEDH, habría de tenerse en cuenta la duración de los malos tratos y de sus efectos físicos o mentales, el sexo de la víctima, su edad, su estado de salud y otras circunstancias que eventualmente pudieran considerarse, en definitiva, la intensidad del sufrimiento ${ }^{27}$.

El TEDH acuña, en el caso Ribitsh c. Austria, de 4 de diciembre de 1995, la expresión, englobadora de todas esas circunstancias, «vulnerabilidad de la víctima» ${ }^{28}$ que sirve para graduar la gravedad del mal trato. La apreciación de la gravedad sería, pues, relativa, dependiendo de esas circunstancias. Y como ya hemos visto, el TEDH ha ido cambiando su apreciación de las circunstancias para ir ampliando el radio de protección brindado por el artículo 3.

Para definir la tortura ${ }^{29}$, el TEDH tiene muy presente el artículo 1 del Convenio de Naciones Unidas contra la tortura de $1984^{30}$ donde se encuentra una pormenorizada

24 Caso Rivas c. Francia, de 1 de abril de 2004, y caso Jalloh c. Alemania, de 11 de julio de 2006.

25 Acerca del sufrimiento psicológico, cfr. VAN Dijk, VAN Hoof, VAN Rijn y ZwaAk (eds.), Theory and Practice of the European Convention on Hiuman Rights, ob. cit., 2006, pp. 416 y ss.

26 Sobre el carácter canónico del caso Irlanda c. el Reino Unido, donde encontramos las primeras definiciones de tortura y tratos inhumanos y degradantes, cfr. G. Cohen-Jonathan, Aspects européens des droits fondamentaux, ob. cit., pp. 70 y ss. Cfr. también sobre este importante caso V. BERGER, Jurisprudence de la Cour européenne des droits de l'homme, Sirey, Paris, 1998, pp. 79 y ss.

27 Sudre, Droit européen et international des droits de l'homme, ob. cit., p.281. También Barcelona Llop, La garantía europea del derecho a la vida y a la integridad personal frente a la acción de las fuerzas del orden, ob. cit., pp. 276 y ss. VAN DIJK, VAN Hoof, VAN RIJN y ZWAAK (eds.), Theory and Practice of the European Convention on Hiuman Rights, ob. cit., 2006, pp. 412 y ss.

28 Al respecto cfr., entre otros, Greer, The Europena convention of Human Rights. Achievement, Problems and Prospects, ob. cit., pp. 235 y ss.

29 A propósito de la jurisprudencia del TEDH sobre la tortura, cfr. SALADO OsUnA, «La tortura y otros tratos prohibidos por el Convenio (art. $3 \mathrm{CEDH}$ )», ob. cit., pp. 89 y ss. G. Portilla Contreras, «De las torturas y otros delitos contra la integridad moral, en M. Cobo Del Rosal (dir.), Curso de Derecho Penal. Parte Especial I, Marcial Pons, Madrid, 1996, pp. 282 y ss. CASAdeval, El Convenio Europeo de Derechos Humanos. El Tribunal de Estrasburgo y su jurisprudencia, ob. cit., pp. 219 y ss.

30 Sobre los convenios internacionales que interactúan con el CEDH, cfr. Di ANDREANA EsPosito, «Art. 3», ob. cit., pp. 74 y 75, y J. Velu y R. ERGEC, La convention européenne des droits de l'bomme: extrait du repertoire du droit belge, tom. VII, Bruyllan, Bruselas, 1990, pp. 195 y 196. En especial cobre la Convención contra la tortura, cfr. C. FERNÁNDEZ DE CASADEVANTES Romani, «Régimen jurídico internacional de la lucha contra la tortura», en Derecho Internacional de los Derechos Humanos, 2. ${ }^{a}$ edición, Diles, S.L., Madrid, pp. 310-316. N. LERNER, «The U.N. Convention on Torture», en Israel Year book on Human Rights, vol. 16, 1986, pp'126-142. W. MAGEE PEDER, «The United Nations Convention against torture and other cruel, inhuman or degrading teatment», en The George Washington Journal of International Law and Economics, vol. 25, n. ${ }^{\circ} 3$, 1992, pp. 809-839. F. MARIÑo MENÉNDEZ, «La Convención contra la Tortura», en F. Gómez IsA y J.A. PASTOR Ridruejo (dirs.), La protección internacional de los derechos humanos en los albores del siglo XXI», Universidad de Deusto, Bilbao, 2003, pp. 243-277. M. TARDU, «The United Nations Convention Against 
descripción y de la que infiere un concepto amplio en el que se identifican un elemento material, uno teleológico y la cualificación del sujeto activo, así como lo señalado por el Comité europeo para la prevención de la tortura ${ }^{31}$. El elemento material lo constituye todo dolor o sufrimiento grave, físico o mental, infligido a una persona. De aquí se colige el criterio de gravedad: para que estemos ante un caso de tortura, es preciso la existencia de gravedad del sufrimiento. Este puede ser físico o mental y aunque a menudo se presentan simultáneamente, basta la presencia de uno de los dos para que pueda ser apreciada la tortura.

El elemento teleológico consiste en la finalidad perseguida por la tortura: obtener información, lograr una confesión, coaccionar o castigar. Este elemento, con ser importante, debe presuponerse siempre que se dan los demás elementos constitutivos del tipo pues si, además de sufrimiento, éste se inflige intencionadamente por funcionario público o persona en el ejercicio de funciones públicas estamos ante tortura. Sumado al elemento objetivo y a la voluntariedad se requiere la cualificación del sujeto activo que debe ser funcionario público o personal al servicio de la autoridad. A pesar de lo anterior, el TEDH ha abierto la posibilidad de considerar tortura los sufrimientos graves infligidos por un particular ${ }^{32}$, derivando la lesión del incumplimiento estatal de su obligación de asegurar que nadie, bajo su jurisdicción, sea afectado en sus derechos humanos.

Alguna doctrina ${ }^{33}$ considera que eximir del requisito de la especial cualificación del sujeto desvirtúa el concepto de tortura, pues no se daría tampoco el elemento teleológico, y entonces lo definitorio de la tortura consistiría únicamente en los sufrimientos graves infligidos voluntariamente, pero, en cambio, otros opinan ${ }^{34}$ lo contrario al entender que tal cualificación del sujeto activo no viene exigida por el Convenio, lo que permitiría acercar la doctrina del TEDH a la de su contraparte interamericana.

Con una gradación de menor gravedad, tras la tortura, se situarían las penas y tratos inhumanos o degradantes ${ }^{35}$ entre los que no es fácil distinguir ${ }^{36}$. Para el TEDH que, en el caso Irlanda contra Reino Unido, había apreciado trato inhumano, pero no tortura, los acaba definiendo como «los sufrimientos físicos o psíquicos provocados voluntariamente

Torture and Other Cruel, Inhuman or Degradaing Treatment or Punishment», en Netherland Journal International Law, vol. 56, 1987, pp. 303 a 321. C. VILLÁN DURÁN, «La convención contra la tortura y su contribución a la definición del derecho a la integridad física y moral en Derecho Internacional», ob. cit., pp. 377 a 395. J. Voyaume, «La convention des Nations Unies contre la torture et autres peines ou traitments cruels, inhumains ou dégradants», en La lutte international contre la torture, Nomos Verlg, Baden-Baden, 1991, pp. 434 a 455.

31 Al respecto cfr. Casadeval, El Convenio Europeo de Derechos Humanos. El Tribunal de Estrasburgo y su jurisprudencia, ob. cit., pp. 217 y ss. Y BARCELONA Llop, La garantía europea del derecho a la vida y a la integridad personal frente a la acción de las fuerzas del orden, ob. cit., 2007, pp. 264 y ss.

32 Caso A. c. Reino Unido, de 23 de septiembre de 1998.

33 La doctrina que critica la ampliación del concepto de tortura: M. L. MAQUeda ABreu, «La tortura y los tratos inhumanos y degradantes», en Anuario de Derecho Penal y ciencias Penales, tomo XXXIX, 1986, p. 430, F. Tomás Y VAliente, La tortura en España: Estudios históricos, Ariel, Barcelona, 1994, p. 244, R. GonZÁlez GonZÁLEZ, El control internacional de la tortura, penas y tratos inbumanos o degradantes, Universidad de Granada, 199, p. 98.

34 SALADO advierte que la restricción no se halla en el CEDH, «La tortura y otros tratos prohibidos por el Convenio (art. 3 CEDH)», ob. cit., p. 90.

35 Casadeval, El Convenio Europeo de Derechos Humanos. El Tribunal de Estrasburgo y su jurisprudencia, ob. cit., pp. 221 y ss.

36 CAnosa, Fix Zamudio y Corzo ponen en duda la utilidad de las distinciones intentadas por el TEDH al referirse al «esfuerzo acaso inútil para distinguir entre tratos crueles, inhumanos y degradantes», ob. cit., pp. 162 a 168. 
con una intensidad particular» ${ }^{37}$. En otra importante decisión se atribuye tal calificación al trato «premeditado, aplicado durante horas y que ha causado importantes lesiones físicas o psíquicas o mentales» ${ }^{38}$. Se requiere sufrimiento de cierta duración, infligido premeditadamente, pero no se exige especial cualificación del sujeto que podría ser un particular, a diferencia de lo que, por regla general, se reclama de las torturas.

Por lo que respecta a las «penas» vedadas por el artículo 3 del Convenio hay que recordar que, del mismo modo que los ordenamientos prohíben la tortura y desde luego no la establecen legalmente como procedimiento común de investigación, tampoco prescriben castigos corporales que puedan infligirse conforme a un procedimiento reglado. Con todo, el TEDH se enfrentó, en el temprano caso Tyrer c. Reino Unido, del 25 de abril de 1978, a una práctica generalizada entonces y aún hoy no completamente erradicada en los ámbitos privados: la de ciertos castigos corporales infligidos a menores; en el caso resuelto era la propia policía la que los ejecutaba en la isla de Man. Sin dudarlo, el Tribunal calificó esa «violencia institucionalizada» como pena vedada por el artículo $3^{39}$.

Los tratos degradantes serían el siguiente y último escalón de gravedad. En los casos Tyrer c. Reino Unido e Irlanda c. Reino Unido, ya citados, el TEDH se refiere al terror, angustia e inferioridad capaz de humillar a la víctima. En Campbell y Cosans c. Reino Unido, de 25 de febrero de 1982, otro caso de castigos infligidos de forma «reglada» en el medio escolar pero que no se llegaron a realizar, el TEDH admite que la «simple amenaza» de recibir un mal trato puede en potencia constituir una lesión. El Tribunal define el trato degradante por el resultado causado a la víctima no por la lesión objetiva en ella producido ya que es la humillación lo constitutivo del trato degradante; y éste se da, aunque no haya habido sufrimiento físico o mental de gran intensidad ${ }^{40}$.

\section{DEBER DE PROTEGER Y DERECHO A LA PROTECCIÓN}

La obligación general que recae sobre los Estados de respeto a los derechos humanos (artículo $1 \mathrm{CEDH})^{41}$ implica una obligación negativa ${ }^{42}$, de abstención de toda interferencia en el ejercicio de tales derechos. En el caso de la prohibición contenida en el artículo 3 , ese componente negativo es claro, porque justamente se trata de una obligación de abstención de las conductas prohibidas ya que expresamente se demanda a los poderes públicos que omitan las torturas y los demás tratos vedados.

Pero al lado, de esta obligación negativa, consustancial a la concepción de los derechos públicos subjetivos, en la jurisprudencia de los máximos tribunales de los derechos y entre ellos, señaladamente, la del TEDH, se ha abierto camino la obligación positiva de

37 Caso Tyrer c. Reino Unido, de 25 de abril de 1978, par. 29.

38 Caso Soering c. Reino Unido, parg. 100; y caso Kudla c. Polonia, de 26 de octubre de 2000; y caso Van der Ven contra Holanda, de 4 de febrero de 2003.

39 Sobre este caso, cfr. Beddard, ob. cit., p. 86. Así mismo, cfr. infra V.6. b).

40 Caso Yankov c. Bulgaria, de 11 de diciembre de 2003.

41 Cfr. por todos, P. A. Fernández SánChez, «El alcance de las obligaciones del Convenio Europeo de Derechos Humanos (art. 1)», en García Roca y Santolaya (coords.), ob. cit., pp. 43 y ss.

42 Obvia, como subraya, SUDRE, Droit européen et international des droits de l'bomme, ob. cit., p. 283. 
proteger los derechos que en el $\mathrm{CEDH}^{43}$ se anudan a lo previsto en su artículo $1^{44}$. Acaba generándose una suerte de derecho a la protección cuya infracción supondría lesión del derecho sustantivo. El derecho a la protección ${ }^{45}$ se encuadraría en el contenido del derecho a la integridad, particularmente en la prohibición del artículo $3 \mathrm{CEDH}$. Por lo demás, este derecho a la protección favorece la eficacia de los derechos convencionales frente a lesiones procedentes de particulares. La infracción combinada del derecho sustantivo con la de la obligación estatal de proteger contra las omisiones o acciones insuficientes de los poderes públicos es el punto de conexión que el TEDH necesitaba para resolver los casos en los que la lesión material procedía de un particular.

En los casos de torturas y tratos inhumanos y degradantes se desglosa ese derecho a la protección no sólo en la adopción de medidas que impidan la violación sino asimismo en los derechos a la investigación y a la sanción, incluso a la protección mediante la aprobación de una ley ${ }^{46}$ protector de la integridad frente a torturas y tratos inhumanos y degradantes o de otro tipo menos lesivo que afecte empero a la vida privada.

Este modo de razonar ha supuesto, en relación con el artículo 3 y con los demás derechos convencionales, que pueda imputarse responsabilidad al Estado aún en los casos en los que la lesión sustantiva fuera producida por un particular. En estos supuestos el Estado sería responsable porque no habría protegido suficientemente ni impedido por lo tanto la lesión del derecho, incumpliéndose la obligación positiva de proteger. Con independencia de si la autoría de la efectiva lesión sustantiva pueda imputarse a un poder público o a un particular, sólo al Estado, al responsable internacional, cabría imputar una infracción que lo sería de su obligación positiva de proteger. Además, el derecho a la protección, reflejo de la obligación positiva de proteger, permite a la víctima acudir al TEDH y obtener satisfacción.

Esta construcción jurisprudencial es particularmente válida en los casos resueltos por el TEDH en los que está en juego la aplicación del artículo 3. Véase el deber de investigar torturas y tratos inhumanos o degradantes que, cuando se incumple, conduce a la declaración de violación, aunque no se hayan podido encontrar pruebas fehacientes. Se trata de una línea de razonamiento puramente constitucional, construida sobre presupuestos distintos a los de la prueba en los procesos penales.

Era por lo demás esperable que el TEDH acabase también considerando una suerte de inversión de la carga de la prueba, de tal manera que tuviera el Estado que demostrar que una persona bajo su custodia no había sufrido malos tratos cuando había indicios de que los hubiera padecido ${ }^{47}$.

43 El Estado está obligado a proteger la integridad de las personas bajo su jurisdicción, adoptando las medidas pertinentes como explica J. A. CARrillo SAlCEDO, «Article 1», en La Convention Européenne des Droits de l'bomme. Commentaire article par article, ob. cit., p. 141. M.-A. EISSEN, «La Cour européenne des droits de l'homme», en Revue de droit public et de sciencie politique, 1987, p. 1586. Cfr. también J. BARCELONA LloP, La garantía europea del derecho a la vida y a la integridad personal frente a la acción de las fuerzas del orden, ob. cit., 2007, pp. 106 y ss. SUDRE, Droit européen et international des droits de l'homme, ob. cit., p. 284. Y CaSAdeval, El Convenio Europeo de Derechos Humanos. El Tribunal de Estrasburgo y su jurisprudencia, ob. cit., pp. 148 y ss.

44 Caso H.L.R. c. Turquía, de 29 de abril de 1997, y caso A. c. Reino Unido.

45 R. Alexy construye el derecho a la protección, Teoría de los derechos fundamentales, CEC, Madrid, 1997, pp. 435 y ss.

46 Caso X e Y c. Holanda, y caso Mahmut Kaya c. Turquía, de 28 de marzo de 2000.

47 Sobre esta inversión de la carga de la prueba, cfr. El Convenio Europeo de Derechos Humanos. El Tribunal de Estrasburgo y su jurisprudencia, ob. cit., p. 218, que comenta al respecto el caso Labita c. Italia, de 6 de abril de 2000. 
En esta línea, se ha ampliado considerablemente el alcance de protección de la integridad frente a torturas y tratos inhumanos o degradantes, al derivar de la obligación de proteger un deber de investigar ${ }^{48}$, es decir, de acometer las acciones necesarias para esclarecer los hechos e identificar y sancionar a los culpables, de suerte que toda renuencia u obstaculización por parte de las autoridades se consideran violatorias del derecho sustantivo. Cuando se incumple esa «obligación procesal» ${ }^{49}$, se declara la vulneración de la vertiente procedimental del derecho ${ }^{50}$ que puede ir o no acompañada de la violación sustancial.

Así el TEDH ha conectado la vulneración del artículo 3 CEDH al incumplimiento por parte del Estado de investigar efectivamente los hechos, de suerte tal que sería la falta de diligencia en la investigación la que provocaría impunidad, lo que constituiría violación del artículo 3 CEDH (caso Ascoy contra Turquía, ya citado, y otros varios casos que desde entonces han consolidado esta doctrina, con especial referencia a los supuestos de detenidos presuntos terroristas), advirtiendo que ni siquiera la lucha contra el terrorismo justifica ninguna limitación.

\section{UN INTENTO DE ORDENACIÓN DE LA CASUÍSTICA JURISPRUDENCIAL: ÁMBITOS DE LA REALIDAD EN LOS QUE SE HA PROYECTADO EL ARTÍCULO 3}

Su ya dilatada historia y el más reciente acceso directo por parte de los justiciables han permitido al TEDH pronunciarse con profusión a propósito del alcance de los derechos convencionales y de manera muy significativa acerca del artículo 3 . Al hacerlo el TEDH ha descartado en ocasiones la infracción del artículo 3, pero ha considerado violentada la integridad, llevando estas lesiones al artículo 8, del que se ha inferido un específico derecho a la integridad al que nos hemos referido antes.

Al abordar el análisis de la doctrina del TEDH relativa a la prohibición del artículo 3 , encontramos un sinfín de sentencias, así que es conveniente ante tal panorama ordenar temáticamente esa jurisprudencia y ofrecer al lector una guía que le permita aprehenderla y comprenderla mejor. En nuestro auxilio el propio Tribunal viene haciendo el esfuerzo de componer unas fichas temáticas que cualquiera puede consultar y que son sumamente útiles ${ }^{51}$. Las que más nos interesan son aquellas que analizan determinadas

También BARCELONA Llop, La garantía europea del derecho a la vida y a la integridad personal frente a la acción de las fuerzas del orden, ob. cit., pp. 128 y ss.

48 Acerca del deber de investigar, cfr. SALADO, «La tortura y otros tratos prohibidos por el Convenio (art. 3 CEDH)», ob. cit., p. 92. GARCÍA RAmírez (coord.), La jurisprudencia de la Corte Interamericana de Derechos Humanos, ob. cit., pp. 852 y ss. BARCELONA LLOP, La garantía europea del derecho a la vida y a la integridad personal frente a la acción de las fuerzas del orden, ob. cit., pp. 77 y ss. Asimismo, L. DoswALD-BECK, Human Rights in Times of Conflict and Terrorism, Oxford University Press, 2012, pp. 222 y ss.

49 Como la denomina SUDRE, Droit européen et international des droits de l'bomme, ob. cit., p. 283. Cfr. también Casadeval, El Convenio Europeo de Derechos Humanos. El Tribunal de Estrasburgo y su jurisprudencia, ob. cit., pp. 230 y ss. 50 Caso Khachiev c. Rusia, de 24 de febrero de 2005. También el caso 97 miembros de la Congregación Testigos de Jehové de Gldani c. Georgia, 3 de mayo de 2007. Sobre los casos similares relativos a España, cfr., en este mismo número de Teoría y Realidad Constitucionales, el estudio de I. Álvarez Rodríguez.

51 https://www.echr.coe.int/Pages/home.aspx?p=press/factsheets\&c=\#n1347890855564_pointer 
situaciones o la condición de ciertos grupos de personas cuya vulnerabilidad los hace proclives a sufrir los tratos vedados por el artículo 3.

Conforme a la pauta señalada, vamos a analizar, primero, la situación de los privados de libertad. También nos ocuparemos de otras generadas por el terrorismo y los conflictos armados, así como de la abundante doctrina del TEDH sobre expulsiones de extranjeros. Asimismo, merece la pena destacar la interesante doctrina del TEDH sobre la violencia doméstica y los casos en los que la protección de la salud ha podido enfocarse desde la perspectiva del artículo 3 .

Además de analizar las situaciones señaladas, puede enfocarse el estudio de la jurisprudencia del TEDH considerando ciertos grupos de población cuya vulnerabilidad es mayor, bien por su debilidad física o por haber venido siendo objeto de una inveterada discriminación. Son los casos de las mujeres, los menores, los gitanos, los discapacitados, los emigrantes y las personas con distinta orientación sexual.

Y como es imposible citar todas las sentencias dictadas sobre el artículo 3 nos limitaremos a subrayar las más importantes y con preferencia las más recientes.

\section{V.1. Personas privadas de libertad}

En general en este apartado los poderes públicos son directos causantes de las violaciones, pero hay algunas excepciones que también analizaremos.

\section{a) Condiciones de los detenidos}

El TEDH ha venido haciendo un esfuerzo sostenido, sobre todo desde principios de siglo, sentando un estándar acerca de estas condiciones y utilizando además la novedosa técnica de los casos piloto. Ello a pesar de que en el CEDH falta un precepto específico que, como hace el artículo 5.2 de la Convención Americana de Derechos Humanos ${ }^{52}$ exija un trato digno a los privados de libertad. Con todo el TEDH ha acabado infiriéndolo ${ }^{53} \mathrm{y}$ particularmente se ha ocupado de las condiciones higiénicas derivadas de la masificación de las cárceles y de las malas condiciones de las instalaciones. En todos estos casos el TEDH se ocupa de valorar si puede apreciarse trato degradante e incluso, en determinadas circunstancias, tortura. Con frecuencia el TEDH cita las recomendaciones del Comité europeo para la prevención de la tortura.

Entre los pronunciamientos más significativos pueden subrayarse los casos Peers c. Grecia, de 19 abril de 2002, y Ananyev y otros c. Rusia, de 10 enero de 2012 (un caso piloto); en este último se juzgan las malas condiciones de detención de personas en prisión provisional, en especial en relación con la falta de espacio. También es un caso piloto Torregiani y otros c. Italia, de 8 enero de 2013, en relación con la falta de espacio según

52 Que establece, luego de la prohibición de torturas y otros tratos vedados, «Toda persona privada de libertad será tratada con el respeto debido a la dignidad inherente al ser humano». Al respecto de este contraste entre ambos tratados, cfr. CANOSA, Fix ZAMUdio y CORZO, ob. cit., pp.153 y ss.

$53 \mathrm{Al}$ respecto, cfr. Sudre, Droit européen et international des droits de l'homme, ob. cit., pp. 292 y ss. CASADEval, El Convenio Europeo de Derechos Humanos. El Tribunal de Estrasburgo y su jurisprudencia, ob. cit., pp. 222 y ss. 
las concretas recomendaciones del Comité europeo para la prevención de la tortura. Sobre lo mismo es reseñable el caso Vargas y otros c. Hungría, de 10 marzo de 2015, otro caso piloto donde se describe el problema estructural de las prisiones húngaras. Por último, es reseñable también el caso piloto Rezmives y otros c. Rumanía, de 25 abril de 2017. En todos estos casos piloto se desvela una mala situación carcelaria generalizada y estructural en los países concernidos

Respecto a los cacheos corporales que el TEDH admite necesarios en ciertas condiciones, pero que estima degradantes si hubiera intención de humillar, como aprecia, entre otros, en los casos Valasinas c. Lituania, de 24 julio de 2001, y El Shennawy c. Francia, de 20 enero de 2011.

También en relación con el aislamiento celular el TEDH admite, por un lado, que es práctica posible, pero que cuando no se respetan ciertos estándares estaríamos incluso ante torturas ${ }^{54}$, o ante trato degradante. ${ }^{55}$

Respecto a los malos tratos, el TEDH se ha pronunciado tanto en casos donde proceden de los guardianes (el más reciente caso Cirino y Renne c. Italia, de 26 octubre de 2017), como en otros en los que son causados por otros detenidos; por ejemplo, el caso Yuriy Illarionovich Schokin c. Ucrania, de 3 octubre de 2013, en el que se aprecia tortura por falta de investigación.

Los traslados repetidos de celda o de edificio por razones de seguridad o por sanción han sido objeto de un escrutinio por parte del TEDH que los ha condenado en varios casos, el último Bamouhammad c. Bélgica, de 17 noviembre de 2015, en el que la víctima fue trasladada 43 veces en seis años.

\section{b) Derecho a la salud de los privados de libertad}

Siguiendo también las recomendaciones del Comité europeo para la prevención de la tortura, el TEDH ha creado una interesante jurisprudencia según la cual el derecho a la salud haya cobertura en el artículo 3 del Convenio. En efecto, mientras que, en relación con las personas en libertad, los contenidos potenciales del derecho a la salud han sido ubicados por el TEDH generalmente en el artículo $8 \mathrm{CEDH}$, cuando se trata de personas privadas de libertad, el Estado tiene obligación de proporcionarles los tratamientos médicos y las medicinas que su condición requiere. Cuando el Estado no cumple con esta obligación respecto a quienes están sometidos a él por esa relación de sujeción especial, entonces hay violación de la prohibición de tratos inhumanos o degradantes.

Hay una buena cantidad de sentencias relativas a enfermos en prisión, sobre todo en casos contra Rusia, pero no sólo. Entre otros, Kondrulin c. Rusia, de 20 septiembre de 2016, o Dorneanu c. Rumanía, de 28 noviembre de 2017. Y en un caso de un enfermo de sida, Aleksanyan c. Rusia, de 22 diciembre de 2008.

El TEDH también se ha referido en numerosas ocasiones a enfermos mentales y en particular con tendencias suicidas. Entre otros, véase el último hasta la fecha: caso Claes c. Bélgica, de 10 enero de 2013.

54 Caso Ilascus y otros c. Moldavia y Rusia, de 8 julio de 2004, Gran Sala.

55 Caso Öcalan c. Turquía (número 2) de 18 marzo de 2014. 
El TEDH ha considerado también que el encarcelamiento de personas mayores con problemas de salud constituye trato inhumano o degradante. Por ejemplo, en el caso Contrada (número 2) c. Italia, de 11 febrero de 2014. Aunque la avanzada edad no otorga por sí misma un derecho a la excarcelación como se estableció en el caso Papon c. Francia, de 7 junio de 2001.

Y aunque el TEDH no ha reconocido un genérico derecho a un tratamiento de sustitución en casos de adicción a las drogas, el TEDH ha juzgado trato inhumano el recibido por toxicómanos en prisión por fallos en la actuación médica ${ }^{56}$.

Incluso el TEDH ha considerado trato inhumano el tabaquismo pasivo sufrido en prisión por uno de los internos en el caso Elefteriadis c. Rumanía, de 25 enero de 2011.

El TEDH ha hecho también un riguroso escrutinio de intervenciones médicas tendentes a obtener medios de prueba en casos de tráfico de drogas, en concreto el suministro de eméticos para la expulsión de bolsas de droga ingeridas por el traficante para eludir el control policial. Aunque el TEDH considera que el tratamiento no es en sí mismo violatorio si se apoya en razones médicas y procesales, analiza la manera de llevarse a cabo por si causase al afectado dolores físicos o sufrimiento mental, lo que implicaría entonces trato inhumano o degradante, como se aprecia en el caso Jalloh c. Alemania, de 11 julio de 2006 (Gran Sala) ${ }^{57}$, pero no en el caso Bagumill c. Portugal, de 7 octubre de 2008.

\section{c) Huelga de hambre de detenidos}

En el caso Nevmerjitki c. Ucrania, de 5 abril de 2005, el TEDH consideró que alimentar por la fuerza a un preso en huelga de hambre constituía tortura. A la misma conclusión llegó en los casos Ciorap c. República de Moldavia, de 19 junio de 2007, y Karabet y otros c. Ucrania, de 17 enero de 2013 (este último un caso de huelga de hambre masiva).

El TEDH recuerda que el artículo 3 obliga a los Estados a preservar la salud de los privados de libertad y proporcionarles los cuidados médicos cuando estén en huelga de hambre, siempre que no se recurra a la alimentación forzosa y haya garantías suficientes.

El TEDH ha llegado incluso a dictar medidas provisionales para asegurar el respeto de los derechos de los reclamantes y sobre todo a exhortarlos a deponer su huelga de hambre ${ }^{58}$.

\section{d) Desaparición forzada de personas}

Una de las manifestaciones más terribles de la privación de libertad es cuando va seguida de la desaparición forzada. Sobre ella versa la gran aportación de la Corte Interamericana a la jurisdicción universal. El TEDH la ha incorporado en algunos casos contra Turquía o Rusia, pero es una incorporación algo tímida, acaso porque el TEDH, en contraste con la Corte Interamericana, carece del recurso que a ésta brinda el reconocimiento

56 Caso Wenner c. Alemania, de 1 de septiembre de 2016.

57 Sobre esta sentencia, cfr. BARCELONA Llop, La garantía europea del derecho a la vida y a la integridad personal frente a la acción de las fuerzas del orden, ob. cit., pp. 251 y ss.

58 Cfr. sobre todos, el caso Ilascu y otros c. República de Moldavia y Rusia, de 8 julio de 2004, Gran Sala. 
expreso del derecho a la integridad (artículo 5 de la Convención Americana de Derechos Humanos). En realidad, lo que el TEDH aprecia en los casos resueltos es el trato inhumano o degradante padecido por las familiares ${ }^{59}$ de los desaparecidos. Así en el caso Kurt c. Turquía, de 25 mayo de 1998, se ampara a la madre de un desaparecido por la angustia sufrida al no saber el paradero de su hijo y por la ansiedad al carecer de información oficial. En posteriores sentencias el TEDH ha matizado esta doctrina ${ }^{60}$.

\section{V.2. Uso de la fuerza en situaciones de terrorismo y conflictos armados}

La gravedad del terrorismo y el pavor que provoca en la sociedad han motivado acciones de los Estados para combatirlo. Tales políticas pueden considerarse a priori legítimas, pero en ningún caso, como advierte el TEDH, podrían justificar la violación de derechos, especialmente de aquellos que, como el que se infiere del artículo 3, son inderogables ${ }^{61}$. Era lógico, pues, que se presentarán casos en Reino Unido, España o Turquía que enfrentaban desde antiguo fenómenos terroristas y fue también lógico que hayan surgido casos en varios países en el marco de la lucha contra el terrorismo islámico.

El caso fundacional fue Irlanda c. Reino Unido, de 18 enero de 1978, uno de los pocos casos de demanda de un país contra otro. El Tribunal consideró tratos inhumanos cinco técnicas de interrogatorio empleadas por las autoridades británicas en Irlanda del Norte. Sin embargo, para que el TEDH apreciase la existencia de tortura hubo que esperar al caso Askoy c. Turquía, ya citado, para que el TEDH apreciase tortura (en el caso la suspensión de una persona con los brazos atados por detrás) de quien se suponía que ayudaba a los terroristas del PKK kurdo. También se apreció tortura en el caso Ocalan c. Turquía, de 12 mayo de 2005, (Gran Sala).

Ya se ha hecho referencia a la violación procedimental del artículo 3 por falta de investigación suficiente, a veces en un lugar secreto, con operaciones de transporte secretas y extrajudiciales que se desencadenaron sobre todo tras las invasiones de Afganistán, como en el caso El-Masri c. "La ex república yugoslava de Macedonia», de 13 diciembre de 2012 (Gran Sala), en la que el Tribunal aprecia tortura en su vertiente sustantiva y asimismo procesal. En este y en otros varios casos similares ${ }^{62}$ se produjo la intervención de la CIA pues se trataba de trasladar a estas personas de los lugares de su aprehensión a centros secretos en Afganistán o en alguna otra parte. Todavía hay asuntos de esta índole pendientes de resolver.

Y si estos casos son de traslado extrajudicial, también hay riesgos en los supuestos en los que el procedimiento de expulsión se ajusta en principio a los cauces legales. Así desde el caso Chahal c. Reino Unido, de 15 noviembre de 1996 (caso de un separatista sikh) o en el caso Chamaiev y otros c. Georgia y Rusia, de 12 abril de 2005 (caso de un

$59 \mathrm{Al}$ respecto, cfr. Casadeval, El Convenio Europeo de Derechos Humanos. El Tribunal de Estrasburgo y su jurisprudencia, ob. cit., p. 232. También Doswald-BECK, Human Rights in Times of Conflict and Terrorism, ob. cit., pp. 214 y ss.

60 Cicek c. Turquía, de 27 febrero de 2001, en Yaas c. Turquía, de 14 noviembre de 2000, y en Timuras c. Turquía, de 6 junio de 2001.

61 Cfr. supra II.

62 Al-Nashiri c. Polonia y Husayn c. Polonia, de 24 julio de 2014, y Nash y Ghali c. Italia, de 23 febrero de 2016. 
checheno extraditado a Rusia) o el caso Aswat c. Reino Unido, de 16 de abril de 2015, donde la víctima, además, es enfermo mental. Entre otros varios casos es interesante el reciente M.A. c. Francia, de 1 de febrero de 2018, a propósito de una extradición a Argelia de un argelino condenado en Francia por terrorismo; además en este caso se produce la desatención de una medida provisional dictada por el TEDH.

También se ha considerado contrario al artículo 3, amén de a otros preceptos convencionales (artículos 8 y 1 del Protocolo 1) la destrucción de casas y bienes de supuestos implicados en acciones terroristas (caso Dulas c. Turquía, de 30 enero de 2001).

Desgraciadamente desde la entrada en vigor del Convenio, en el ámbito europeo se han producido conflictos armados que han supuesto violación del derecho a la vida (artículo $2 \mathrm{CEDH}$ ) o implicado tratos vedados por el artículo 3. El TEDH incluso se ha ocupado de hechos acontecidos con anterioridad a 1950, como el de las fosas de Katyn ${ }^{63}$, aunque en este asunto el TEDH, por razón de la competencia temporal, sólo pudo apreciar violación del artículo 38 del Convenio.

La invasión turca del norte de Chipre generó diversos asuntos a partir del inaugural caso Chipre c. Turquía, de 10 mayo de 2001 (Gran Sala), en el que, entre otras violaciones, se apreció la del artículo 3 por falta de investigación y, sustantivamente, por el tratamiento inhumano infligido a los grecochipriotas residentes en el territorio de la isla ocupado por Turquía a partir de 1974. En el caso Varnava y otros c. Turquía, de 18 septiembre de 2009 (Gran Sala), el Tribunal aprecia violación del artículo 3 por los sufrimientos de los familiares de los desaparecidos como consecuencia de la ocupación.

Hay otros varios casos de malos tratos infligidos a familiares de desaparecidos en asuntos relativos a la represión turca contra el terrorismo kurdo ${ }^{64}$, así como casos de destrucción de casas y bienes ${ }^{65}$.

Por su parte la represión rusa en Chechenia ha generado un aluvión de pronunciamientos en los que, además de violaciones del derecho a la vida, se declara la violación de la prohibición de torturas y tratos inhumanos y degradantes, incluyendo desapariciones que implicaron trato inhumano de los familiares de los desaparecidos, por ejemplo, en el caso Abdulkhanov c. Rusia, de 3 octubre de 2013.

El Tribunal se ha ocupado de la intervención de fuerzas internacionales en diversos conflictos, entre estos casos destaca Al-Saadoon y Mufdhi c. Reino Unido, de 2 marzo de 2010, en el que se condena al país europeo por extraditar a Irak a dos iraquíes sospechosos de haber asesinado a dos soldados británicos; había riesgo de que los extraditados sufrieran torturas o tratos inhumanos. En contraste, no aprecia lesión de los derechos convencionales alegados en el caso Hassan c. Reino Unido, 16 septiembre de 2014 (Gran Sala), en el que el TEDH entra a valorar la actuación de las fuerzas militares británicas en Irak, en un interesante supuesto de aplicación extraterritorial ${ }^{66}$ del Convenio.

Y quedan pendientes de resolución algunos casos concernientes a los conflictos suscitados en Ucrania en los últimos años.

63 Matanza de oficiales polacos en 1940 por parte de fuerzas soviéticas: caso Yanowwiec c. Rusia, de 21 octubre de 2013, Gran Sala.

64 Caso Er y otros c. Turquía, de 16 abril de 2013.

65 Casos Orhan c. Turquía, de 18 junio de 2002, o Benter y otros c. Turquía, de 12 noviembre de 2013.

66 Como analizan Van Dijk, Van Hoof, Van Rijn y ZwaAK (eds.), Theory and Practice of the European Convention on Hiuman Rights, ob. cit. pp. 19 y ss. 


\section{V.3. Extradiciones y expulsiones}

Aunque el $\mathrm{CEDH}$ no incorpora el principio de non refoulement que otros tratados contemplan ${ }^{67}$ el TEDH ha acabado de una suerte u otra integrándolo, apelando a diversos artículos del CEDH, entre ellos al artículo $3^{68}$. Es fundacional el caso Soering c. Reino Unido, ya citado, en el que el TEDH consideró que la previsible estancia del reclamante, si se produjera la extradición, en el llamado «corredor de la muerte» constituiría un trato inhumano y degradante. El TEDH valora el sistema penal y penitenciario norteamericano, lo que hará en varias ocasiones.

Igualmente, el Tribunal considera, en el caso H.I.R. c. Francia, de 27 abril de 1997, que el Estado colombiano no podría proteger al traficante de este país si fuera expulsado por Francia.

En la estela del caso Soering, pero con pronunciamientos en sentido inverso, el TEDH ha rechazado entrar en el fondo de varios casos y consideró que no había violación del artículo 3; en estos casos se planteaba que la extradición a Estados Unidos, con riesgo de ser condenado a muerte o prisión perpetua, entrañaba trato inhumano degradante ${ }^{69}$.

Sin embargo, en el caso Trabelsi c. Bélgica, de 4 septiembre de 2014, el Tribunal parece girar de nuevo su jurisprudencia. La víctima del caso es un tunecino que, dada la magnitud de sus presuntos crímenes, podía ser condenado a perpetuidad. El Tribunal recuerda que la prisión permanente es conforme al Convenio siempre y cuando exista un mecanismo que permita, a petición del afectado, su revisión para una eventual conmutación. En el caso de los Estados Unidos, aunque cabe una improbable gracia presidencial, no existe posibilidad para el condenado de solicitar un reexamen de su situación; así que se enjuicia negativamente de nuevo, como ya ocurrió en el caso Soering, el sistema penal estadounidense por considerarlo fuera de los estándares europeos.

\section{V.4. Violencia doméstica}

Sobre este tipo de violencia que sufren las mujeres y los hijos en el seno de la familia el TEDH ha tenido ocasión de pronunciarse. Así en el caso Talpis c. Italia, de 2 marzo de 2016, la muerte del hijo y la tentativa de asesinato de la mujer pusieron de manifiesto la negligencia de las autoridades italianas que no protegieron debidamente a las víctimas de los actos de violencia doméstica protagonizados por el victimario. Por todo ello se considera vulnerado tanto el artículo 2 como el artículo 3. Asimismo, en el caso E.S. c. Eslovaquia, de 15 diciembre de 2009, el Tribunal entiende que el Estado no prestó la protección inmediata que la demandante y sus hijos necesitaban, lo que supuso desatender las obligaciones positivas que se derivan de la interpretación sistemática de los artículos 1 y 3 del Convenio.

67 Sobre el particular, cfr. VAN DijK, VAN HoOf, VAN Rijn y ZwaAK (eds.), Theory and Practice of the European Convention on Hiuman Rights, ob. cit., pp.427 y ss. Doswald-BECK, Human Rights in Times of Conflict and Terrorism, ob. cit., pp. 214 y ss. SALAdo, ob. cit., pp. 105 y ss. D. Boza Martínez, Los extranjeros ante el Convenio Europep de Derechos Humanos, Universidad de Cádiz, 2007, pp. 110 y ss.

68 Acerca de esta doctrina del TEDH, cfr. SAntolaya MachettTi, P., El derecho de asilo en la Constitución española, Lex Nova, Valladolid, 2001, pp. 134 y ss. Cfr. También Van Dijk, Van Hoof, Van Rijn y ZwaAK (eds.), Theory and Practice of the European Convention on Hiuman Rights, ob. cit., 2006, pp. 433 y ss.

69 El último, caso Harkins c. Reino Unido, de 10 de julio de 2017. 
En casos de violencia doméstica, como en el caso E.M. c. Rumanía, de 30 octubre de 2012, el TEDH apreció vulneración procedimental del artículo 3 dada la pasividad de los tribunales rumanos. Algo parecido sucedió en el caso Valieuliene c. Lituania, de 26 marzo de 2013, porque el fiscal finalizó la instrucción sin dar ocasión a la depuración de los hechos.

\section{V.5. Protección de la salud}

Ya hemos visto más atrás ${ }^{70}$ cómo el derecho a la salud en relación con personas privadas de libertad es conectado por el TEDH con el artículo 3. Esta misma conexión es realizada también en casos en los que la potencial víctima no está privada de libertad ${ }^{71}$. Ya en el caso Herczelfaluy c. Austria, de 29 septiembre de 1992, el TEDH se pronunció sobre la aplicación por la fuerza de un tratamiento médico en un hospital psiquiátrico; el Tribunal consideró que había una justificación médica para preservar la salud del enfermo y que este no estaba en pleno uso de sus facultades. A sensu contrario se desprende que un paciente capaz debe aceptar el tratamiento —el consentimiento informado-, como varias sentencias posteriores han confirmado, la última A. P., Garçon y Nicot c. Francia, de 6 abril de 2017.

En el caso Dvoracek c. República Checa, de 6 noviembre de 2004, el TEDH no aprecia vulneración del artículo 3 en la aplicación de un tratamiento médico sexológico con antiandrógenos que respondía a una necesidad terapéutica y al que el paciente, en principio, había prestado consentimiento. En contraste, el TEDH, en el caso Elberte c. Letonia, de 13 enero de 2015, encuentra trato inhumano o degradante de una mujer a cuyo marido le habían extraído los tejidos corporales tras su muerte con fines de investigación. Se aprecia falta de claridad de la legislación letona, así como de consentimiento en el caso.

Sin embargo, en otro caso $^{72}$ el TEDH no ha llegado tan lejos como para considerar que la denegación del acceso a un tratamiento anticanceroso experimental constituyese violación ni del artículo 3 ni del artículo 8 . Tampoco se aprecia vulneración del artículo $3 \mathrm{CEDH}$, aunque sí del artículo 8, en la actuación del Estado noruego en relación con los submarinistas que participaron en los pasos pioneros de la estación petrolífera en el Mar del Norte y que corrieron graves riesgos que, empero, no estaban entonces definidos ${ }^{73}$.

Finalmente hay que tratar aquí determinadas expulsiones de extranjeros enfermos acerca de las cuales el TEDH ha valorado si la expulsión podía constituir una vulneración del artículo 3. Así lo consideró en el caso D.C. c. Reino Unido, de 2 mayo de 1997, en el que un enfermo de sida es puesto en libertad en Gran Bretaña tras cumplir una pena de prisión y se decreta su expulsión a Saint-Kitts. El TEDH valora las condiciones hospitalarias en este país y, dadas las circunstancias excepcionales del caso, aprecia que la expulsión vulneraría el artículo 3.

70 Cfr. supra V.2. b).

71 En general a cerca de los casos médicos, cfr. Van Dijk, VAN Hoof, VAn Rijn y ZwaAk (eds.), Theory and Practice of the European Convention on Hiuman Rights, ob. cit., 2006, pp. 440 y ss.

72 Hristozov c. Bulgaria, de 13 noviembre de 2012.

73 Vilnes y otros c. Noruega, de 5 de diciembre de 2013. 
Algo parecido ocurrió en el caso Paposhivili c. Bélgica, de 13 diciembre de 2016 (Gran Sala). El TEDH aprecia trato inhumano o degradante en el hecho de prohibir la entrada y reenviar a su país a un georgiano enfermo de leucemia a cuya familia, sin embargo, se había autorizado a residir en Bélgica, con lo cual se les separaba y se privaba a la víctima de contar con el apoyo moral de los suyos.

En contraste, la Gran Sala, en el caso N. c. Reino Unido, de 27 mayo de 2008, no aprecia violación del artículo 3 en la expulsión de una enferma de sida ugandesa que, antes de que la expulsión fuera efectiva, estuvo atendida durante los nueve años que tardó su caso en resolverse judicialmente. El TEDH no halla aquí las circunstancias excepcionales que apreció en el caso D. c. Reino Unido, ya citado, y afirma que los Estados parte no tienen la obligación de paliar las disparidades con los tratamientos médicos disponibles en los Estados no parte del Convenio.

En el interesante caso Pretty c. Reino Unido, ya citado ${ }^{74}$, el Tribunal se enfrenta al problema del suicidio desde varios artículos convencionales y también desde la óptica del artículo 3. La víctima era una enferma incurable que, imposibilitada, necesitaba la ayuda de su marido para suicidarse, pero tal ayuda estaba sancionada penalmente en Gran Bretaña. El Tribunal considera, por un lado, que del derecho a la vida no se infiere el derecho a morir ni menos el derecho a ser ayudado para morir y, por otro, que la situación en la que se encuentra la víctima, aún siendo deplorable, no constituye un trato inhumano o degradante que pueda imputarse a las autoridades británicas.

\section{V.6. Las personas más vulnerables}

En diversas ocasiones el TEDH ha destacado la vulnerabilidad de las víctimas para apreciar la lesión y, en relación con el artículo 3, lo ha hecho reiteradamente. Por eso está justificado un tratamiento de la jurisprudencia del Tribunal según los grupos de población en los que las víctimas se encuadran, siempre y cuando la jurisprudencia tenga el volumen suficiente para justificar tal tratamiento autónomo. En otras palabras, no todos los tipos de personas serán abordados aquí separadamente, sólo aquellos acerca de los cuales el Tribunal se haya pronunciado reiteradamente en relación con el artículo 3.

\section{a) Mujeres}

Es el grupo de población mayor y posiblemente el que más atención ha recibido del TEDH desde la óptica del artículo 3. Algunas referencias hemos hecho ya al tratar la violencia doméstica que también afectaba a los hijos ${ }^{75}$. Aquí daremos cuenta de situaciones que implican únicamente a las mujeres. Muchas de estas vulneraciones fueron protagonizadas directamente por las autoridades, como en los casos de violencia policial, así por ejemplo el caso de una menor que sufrió un examen ginecológico humillante durante su detención como en el caso Yazgül Yilmaz c. Turquía, de 1 de enero de 2011, o en el caso Alfet Süreyya Eren c. Turquía, de 10 octubre de 2015, en el que una activista de un

74 Cfr. supra I.2.

75 Cfr. supra V.4. 
partido ilegal es, según el TEDH, torturada, amén de que asimismo hay vulneración procedimental por falta de investigación.

En algunas situaciones enjuiciadas por el Tribunal la violencia policial alcanza cotas terribles de tortura, como en el caso Aydin c. Turquía, de 25 septiembre de 1997, con violación sexual y palizas a una menor. Otro caso similar es Mslava y Nalbandov c. Rusia, de 24 enero de 2008.

Por otro lado, son muchos los casos en los que la vulneración del artículo 3 se produce por la falta de protección ante violaciones y abusos sexuales cometidos por particulares, bien porque no fueron investigados o el procedimiento judicial no fue efectivo ${ }^{76}$. Y también es destacable el caso P. y S. C. c. Polonia, de 30 octubre de 2012, en el que las víctimas, menores de edad que habían sido violadas y no recibieron consejo médico en vista de un posible aborto, y una de ellas recibió de las autoridades un trato que el Tribunal considera inhumano o degradante.

Por lo que concierne a la violencia infligida por particulares el TEDH aprecia violación procedimental de la prohibición de tratos inhumanos o degradantes en la falta de investigación y enjuiciamiento adecuado del asalto a una mujer que fue rociada con ácido. ${ }^{77}$

También se consideran violación del artículo 3 los malos tratos, especialmente psicológicos, sufridos por una mujer mayor que vivía sola, por parte de una banda criminal sin que el Estado cumpliese con su obligación de protegerla ${ }^{78}$

El TEDH, aunque se ha pronunciado sobre las mutilaciones genitales de las mujeres, como eran en relación con casos de extradición o expulsión, han concluido en la no violación ${ }^{79}$.

En otros casos de expulsión el TEDH consideró la violación en R. D. c. Francia, de 16 junio de 2016, en el que la víctima corría riesgo grave en su país de origen (Guinea Conakry) de sufrir la represalia de su familia, musulmana, por haberse casado con un cristiano. También aprecia violación en caso de expulsión por riesgo de exclusión social en su país, e incluso con riesgo de ser condenada a muerte o a prisión, de una mujer afgana a causa de haber mantenido una relación extramatrimonial en Suecia ${ }^{80}$.

En relación con el derecho a la procreación, ubicado en principio dentro del artículo 8 CEDH, el TEDH se ha referido a él también desde el ángulo del artículo 3. Además de los casos de esterilización practicada sin el consentimiento informado y que afectaban a mujeres gitanas ${ }^{81}$, el Tribunal ha considerado, en el caso R.R. c. Polonia, de 26 mayo de 2011, violación del artículo 3 y del artículo 8 en la situación que tuvo que padecer una mujer que no pudo acceder a tiempo a las pruebas fetales que determinarse si el feto sufría malformación. La violación del artículo 3 radicó en el trato humillante que la reclamante recibió de los médicos y en el pésimo funcionamiento de los servicios médicos. Generalmente, los casos de aborto han sido considerados por el Tribunal desde el ángulo del artículo 8, aunque sin llegar nunca a deducir de él un específico derecho a abortar.

\footnotetext{
76 Hay muchos casos de los cuales el último: B. V. c. Bélgica, de 2 mayo de 2017.

77 Caso Ebcin c. Turquía, de 1 de febrero de 2011.

78 Caso Irina Smirnova c. Rusia, de 13 octubre de 2016.

79 Véase, por todos, el caso Sow c. Bélgica, de 19 enero de 2016.

80 Caso N. c. Suecia, de 20 julio de 2010.

81 Cfr. infra V.6. c).
} 


\section{b) Menores}

El TEDH se ha ocupado frecuentemente de los menores. Así ha sancionado su ubicación en prisiones para adultos y también ha apreciado las malas condiciones de los lugares donde eran recluidos ${ }^{82}$; y ha prestado en los últimos tiempos especial atención a las situaciones de los menores, acompañados o no, que llegan a Europa de manera irregular o en demanda de asilo procedentes de países diversos como Chechenia, Sri Lanka, Kazagistán, Afganistán, Irak u otros. El TEDH valora las condiciones a las que son expuestos estos menores ${ }^{83}$. En relación con los menores no acompañados, el escrutinio del Tribunal es todavía más estricto ya que su grado de vulnerabilidad en tales ocasiones es aún mayor ${ }^{84}$. Tanto en unos como en otros el Tribunal, con el apoyo de las recomendaciones del Comité europeo de prevención de la tortura, aprecia tratos inhumanos o degradantes debido a las pésimas condiciones (masificación, falta de higiene, compañía de adultos, entre otros) que han de soportar los menores en los lugares de internamiento donde son confinados.

Por otro lado, el TEDH abordó hace cincuenta años el entonces polémico asunto de los castigos físicos que podían infligirse a los niños para corregirlos y que con frecuencia eran consentidos por los ordenamientos jurídicos ${ }^{85}$. Pues bien, el Tribunal abogó por la prohibición de este tipo de correctivos de índole física. En el caso Tyrer c. Reino Unido, ya citado, se considera contraria al artículo 3 la pena de azotes en el trasero qué tenía que administrar la policía a un adolescente de 15 años como sanción por haber herido a un alumno de su escuela.

Y si en el caso anterior estaríamos ante la violencia institucionalizada que era legalmente administrada, también había que proscribir todo castigo corporal a los menores que infligieran particulares, señaladamente los padres o tutores o los profesores, como se subraya en el caso A. c. Reino Unido, del 23 de septiembre de 1998. En este caso se pone de manifiesto cómo en relación con las personas vulnerables, aquí menores, el Estado tiene obligación de protegerlas, también frente a ataques perpetrados por particulares. Así, en materia de violaciones u otros maltratos de índole sexual, el TEDH ha considerado frecuentemente y, sobre todo, además de la violación sustantiva, la violación procedimental ligada justamente a esa obligación positiva ${ }^{86}$.

Y la misma obligación de proteger persiste respecto a los malos tratos en las escuelas, ya públicas ya privadas, ${ }^{87}$, como asimismo en otras ocasiones cuando ha habido un funcionamiento deficiente de los servicios sociales que no pusieron remedio a la precaria situación de las víctimas en el seno familiar ${ }^{88}$ o en situaciones acaso más dramáticas ${ }^{89}$.

82 Por ejemplo, en el caso Coselav c. Turquía, de 9 octubre de 2012.

83 Respecto a los menores acompañados véase, entre otros, el caso Muskhadzhiyeva y otros c. Bélgica, de 19 enero de 2010, o el caso S. F. y otros c. Bélgica, de 7 diciembre de 2017.

84 Véanse los casos Mahamad c. Grecia, de 11 diciembre de 2014, y Abdullahi Elmi y Aweys Abubakar c. Malta, de 22 noviembre de 2016.

85 Cfr. supra, III.

86 Cfr., entre otros varios, el caso I.C. c. Rumanía, del 24 de mayo de 2016.

87 Cfr. el caso O'Keeffe c. Irlanda, de 28 de enero de 2014, Gran Sala.

88 Caso Z. y otros c. Reino Unido, de 10 de mayo de 2001, Gran Sala.

89 Caso V.C. c. Italia, de 1 de febrero de 2018 en el que la víctima cayó en una red de prostitución infantil. 


\section{c) Gitanos}

Otro de los grupos vulnerables a los que el Tribunal ha prestado especial atención es el de los gitanos o gentes de viaje o roms, cuya vulnerabilidad radica sobre todo en haber sufrido desde tiempos inveterados discriminación racial. La jurisprudencia del TEDH sobre ellos concierne a muchos de los preceptos convencionales, pero especialmente a su artículo 3, en relación con el cual el TEDH ha tenido ocasión de pronunciarse sobre ataques a la integridad de los gitanos, perpetrados tanto por agentes del Estado como por particulares. Y salvo alguna excepción, son situaciones acaecidas en países del antiguo bloque soviético o en los de la antigua Yugoslavia.

Son varios los ejemplos de brutalidad policial perpetrada en casos de detención; y con frecuencia, a la vulneración sustantiva se suma la violación procedimental, debida a la falta de adecuada investigación. ${ }^{90}$

Una de las más humillantes manifestaciones de racismo que han sufrido los gitanos ha sido la esterilización forzada de sus mujeres. En varios casos contra Eslovaquia el Tribunal ha considerado la violación del artículo 3, a menudo combinada con la del artículo 8 por falta de consentimiento informado al tratamiento médico esterilizante ${ }^{91}$.

Merece la pena recordar un caso terrible sobre el que el TEDH no pudo resolver en plenitud debido a que, cuando sucedieron los hechos en 1993, Rumanía no era aún parte del Convenio. Se trató de un linchamiento de tres hombres gitanos por una multitud en la que participaban el comandante de la policía y algunos de sus agentes. Fueron después destruidas las casas y los bienes de los gitanos por esa multitud espoleada por la policía; y finalmente expulsados los supervivientes. Sólo algunos de ellos fueron, diez años más tarde, resarcidos por los daños sufridos. Como en otros casos resueltos por el TEDH, el principal derecho concernido era el derecho a la vida, pero por la razón señalada el Tribunal no pudo declarar su violación. Encontró, sin embargo, un resquicio para considerar que las condiciones de vida después de lo sucedido en 1993 constituían una violación de los artículos 3 y 8 del Convenio.

Por lo que concierne a los actos de violencia contra los gitanos cometidos por particulares, el TEDH suele apreciar, por un lado, falta de protección suficiente, es decir, desatención a la obligación positiva que recae sobre los Estados, y violación procedimental del artículo 3. Todo motivado por el origen étnico de las víctimas, lo que lleva al Tribunal a considerar también vulnerado el artículo 14 del Convenio (prohibición de discriminación) ${ }^{92}$.

\section{d) Discapacitados}

En varias ocasiones el TEDH se ha ocupado de las condiciones de detención de personas discapacitados cuya vulnerabilidad es mayor ${ }^{93}$. Los estándares fijados se han

90 Entre otros véanse los casos Cobzaru c. Rumanía, y Adam c. Eslovaquia, ambos de 26 julio de 2016. En ocasiones, la violación del artículo 3 va de la mano de la del artículo 2 cuando la víctima fallece durante la detención.

91 Véanse los casos V.C. c. Eslovaquia, de 8 noviembre de 2011; N.B. c. Eslovaquia, del 12 junio de 2012; y I.G. c. Eslovaquia, de 13 noviembre de 2012.

92 Entre otros véanse los casos Secia c. Croacia, de 31 mayo de 2007, y Skorjanec c. Croacia, de 28 marzo de 2017.

93 Entre otros muchos véanse los casos Price c. Reino Unido, de 10 julio de 2001, o el caso Topekhin c. Rusia, de 10 mayo de 2016. 
llevado también a casos de internamiento en residencias para personas con problemas mentales $^{94}$.

El caso Dordevic c. Croacia, de 24 julio de 2012, ofrece un interesante supuesto de eficacia entre particulares, pues la condena se debe a la inacción de las autoridades para poner fin y remediar una situación de acoso a un niño por parte de otros niños de su vecindad.

La vulnerabilidad de este tipo de personas que se exponen también a sufrir un trato inhumano en caso de expulsión es grande, como acontece en el caso Aswat c. Reino Unido, de 16 abril de 2015, en el que un esquizofrénico paranoico, implicado en el extremismo islámico, corría riesgo si el Reino Unido lo extraditada a los Estados Unidos. Una vez más se descalifica el sistema penitenciario norteamericano.

También los discapacitados son más vulnerables a los ataques sexuales, sobre alguno de los cuales se ha pronunciado el Tribunal. Por ejemplo, en el caso I.C. c. Rumanía, de 24 mayo de 2016, en el que el TEDH encuentra graves deficiencias en la instrucción judicial del caso. También es muy llamativo el ya citado ${ }^{95}$ caso X. e Y. c. Holanda, en el que se aprecia violación del artículo 3 por falta de una legislación penal que, en el momento de producirse los hechos, castigase los abusos sexuales de una menor discapacitada mental por parte de otros internos en la residencia que compartían.

\section{e) Emigrantes}

Los emigrantes en general y los menores emigrantes en particular conforman otro grupo vulnerable que ha merecido reiterada atención del TEDH que sobre ellos ha dictado muchas sentencias, sobre todo en relación con Grecia. El Tribunal no discute el derecho que los Estados tienen de controlar el acceso de extranjeros a su territorio, así como su facultad de expulsarlos cuando han ingresado en él irregularmente. Sin embargo, el TEDH enjuicia las condiciones en las que los extranjeros son confinados y en numerosas situaciones ha apreciado trato inhumano o degradante, acompañando a veces su decisión con la declaración de vulneración del artículo 5.1 (derecho a la libertad) o del artículo 13.1 (derecho a un recurso efectivo). Se analizan las situaciones en las zonas de tránsito de los aeropuertos ${ }^{96}$, o en otras dependencias oficiales ${ }^{97}$. Se aprecia la masificación, la falta de higiene o de ventilación, entre otras malas condiciones de confinamiento. Y una de las circunstancias que el TEDH considera es la vulnerabilidad de la víctima, obviamente mayor en los emigrantes menores a los que ya hemos hecho referencia ${ }^{98}$.

En el marco de la Unión Europea sin fronteras internas, la entrada irregular de emigrantes que se desplazan de un Estado a otro motivó la creación de una legislación comunitaria (el ahora polémico reglamento de Dublín en sus sucesivas versiones) a la que, además de los Estados miembros, se adhirieron Noruega, Islandia, Suiza y Liechtenstein. Mediante esta norma se determina que el Estado por el que entró en la Unión un

94 Caso Staner c. Bulgaria, Gran Sala, de 17 enero de 2012.

95 Cfr. supra I.2.

96 Entre otros, el caso Z.A. y otros c. Rusia, de 28 marzo de 2017, enviado a la Gran Sala.

97 Caso Dougoz c. Grecia, de 6 marzo de 2001.

98 Cfr. supra V.6. b). 
ciudadano de un tercer Estado es el responsable de examinar su demanda de asilo. Se prevé el reenvío desde un Estado al Estado responsable de decidir sobre la petición, evitándose así la reiteración de las demandas de asilo.

El Tribunal ha juzgado el funcionamiento de este mecanismo comunitario y ha apreciado violación del artículo 3 en varios casos en los que, o bien no había garantías de un trato adecuado en el país receptor ${ }^{99}$, o bien en el país emisor no se respetaron las exigencias derivadas del artículo $3^{100}$.

\section{f) Diferente orientación sexual}

Otro grupo vulnerable y objeto de tradicional discriminación es el de las personas LGTBI. Por ello, cuando el TEDH aprecia lesión de algún derecho convencional suele considerar simultáneamente la violación de la prohibición de discriminación (artículo 14). Así sucede, por ejemplo, en el caso Identuba y otros c. Georgia, de 12 mayo de 2015, en el que las víctimas, que participaban en una manifestación contra la homofobia, fueron atacadas por contramanifestantes ante la pasividad policial. A estos hechos siguió una falta de investigación adecuada.

Es interesante también la jurisprudencia del TEDH sobre transgéneros que corona, por el momento, la sentencia en el caso A.P., Garçon y Nicot c. Francia, ya citado. En ella el TEDH considera la violación del artículo 8 en relación con uno de los recurrentes, pero contempla en potencia la del artículo 3, al establecer que la esterilización impuesta a los transgéneros para obtener el cambio de sus documentos oficiales constituiría un trato inhumano o degradante.

\section{CONCLUSIÓN}

La prohibición de la tortura nace ligada a la aparición del Estado liberal y se incorpora al Derecho internacional de los derechos humanos como derecho fuerte, inderogable en los términos del artículo 15.2 del Convenio.

Como es obvio las situaciones contra las que la prohibición fue imaginada se han ido ampliando, Así que ha sido preciso efectuar una interpretación evolutiva para enfrentar esas situaciones nuevas, al tiempo que se continuaba protegiendo frente a los clásicos abusos de los agentes estatales. En definitiva, hay que afrontar los peligros antiguos y los nuevos y hacerlo con un estándar más exigente con los malos tratos, en la medida en la que la sensibilidad social ya no tolera lo que toleraba antes, por ejemplo, la violencia doméstica.

Como ha ocurrido en relación con otros preceptos del Convenio, el TEDH ha interpretado sistemáticamente el artículo 3 junto con el 1 para proyectar la tutela del primero a supuestos en los que el victimario era un particular. Y para este tipo de casos y también

99 Por ejemplo, en los casos M.S.S. c. Bélgica y Grecia, de 21 enero de 2011 (Gran Sala), o Sharifi y otros c. Italia y Grecia, de 21 octubre de 2014.

100 Casos Mohammed c. Austria, de 6 junio de 2013, o Tarakhel c. Suiza, de 4 noviembre de 2014, ambos casos de la Gran Sala. 
para aquellos en los que la directa comisión de la violación pueda imputarse a un agente del Estado, el Tribunal elaboró la noción de violación procedimental del artículo 3, consistente en la consideración de la lesión, aun cuando no haya constancia de ella, si el Estado no investigó suficientemente los hechos denunciados o los tribunales no actuaron diligentemente. Vemos aquí la diferencia entre la determinación como ilícito penal de unos hechos (lo que requiere prueba fehaciente de su comisión por algún sujeto) y su declaración como ilícito internacional a la luz del Convenio. Parece además tratarse de la manifestación de una suerte de derecho a la protección que el Estado ha de brindar frente a los tratos vedados por el artículo 3 que, cuando no ha funcionado para evitar el daño, ha de activarse para hallar un remedio que pasa por una correcta investigación y eventual sanción de los responsables.

Con todo, el TEDH ha estado vigilante para evitar que ciertas prácticas, por ejemplo, contra los gitanos o los homosexuales, entre otros, que son aún frecuentes en algunas sociedades, tuviera su visto bueno. Antes al contrario, el Tribunal no ha dudado en imponer un estándar europeo en relación con el artículo 3, pero no solo, aunque no fuera claro el consenso europeo y pudiera esgrimirse el margen de apreciación.

Por lo demás, esa tarea no sido fácil cuando se enfrentan problemas tan arduos como los planteados por el terrorismo o la emigración que las sociedades europeas ven como grandes amenazas y que, sin la vigilancia del TEDH, acaso llevasen a algunos Estados a consolidar prácticas más que discutibles.

TITLE: The probibition of torture and inbuman treatments in the ECHR

ABSTRACT: This is an analysis of one of the crucial articles of the ECHR that takes part of the core of non-derogable rights in the terms of Article 15.2 of the Treaty. We have to admit that this provision does not completely protect personal integrity (for protecting the rest of the integrity the ECtHR uses Article 8), but a part of it in the face of the most serious attacks, and that it does so, not through the explicit recognition of a right but by establishing a probibition from which is inferred, by reflection, a right that bolders can finally defend in the European Court of Human Rights.

RESUMEN: Se trata de un análisis de uno de los artículos cruciales del CEDH que forma parte del núcleo de los derechos inderogables en los términos del artículo 15.2 del Tratado. Es verdad que este precepto no protege la integridad personal en su totalidad (para proteger el resto de la integridad el TEDH utiliza el artículo 8), sino una parte de ella frente a los ataques más graves, y que lo hace, además, no mediante el reconocimiento expreso de un derecho sino a través de una probibición de la que se infiere, por reflejo, un derecho que los titulares pueden defender, en último término, ante el Tribunal Europeo de Derechos Humanos.

KEY WORDS: European Convention on Human Rights; European Court of Human Rights; torture or inbuman or degrading treatment or punishment.

Palabras CLAVE: Convención europea de Derechos Humanos; Tribunal Europeo de Derechos Humanos; penas y tratos inbumanos o degradantes.

FECHA DE RECEPCIÓN: 14.07.2018

FECHA DE ACEPTACIÓN: 13.09 .2018 
